\title{
The effect of tourniquet deflation on hemodynamics and regional cerebral oxygen saturation in aged patients undergoing total knee replacement surgery
}

\author{
Inkyung Song, Dong Yeon Kim, and Youn Jin Kim \\ Department of Anesthesiology and Pain Medicine, School of Medicine, Ewha Womans University, Seoul, Korea
}

Background: Inflation and deflation of a pneumatic tourniquet used in total knee replacement surgery induces various changes in patient's hemodynamic and metabolic status, which may result in serious complications, especially in aged patients. Near-infrared spectroscopy (NIRS) is a monitoring device designed to estimate the regional cerebral oxygen saturation. We evaluated the effect of tourniquet deflation on hemodynamics and regional cerebral oxygen saturation in aged patients undergoing total knee replacement surgery, using NIRS.

Methods: Twenty-eight American Society of Anesthesiologists physical status I or II patients, over the age of sixtyfive years undergoing total knee replacement surgery, were included. Under general anesthesia, the mean arterial pressure (MAP), heart rate (HR), cardiac output (CO), stroke volume (SV), and regional cerebral oxygen saturation $\left(\mathrm{rSO}_{2}\right)$ were recorded before induction of anesthesia and every $2 \mathrm{~min}$ after tourniquet deflation for $20 \mathrm{~min}$. Arterial blood gas analysis was performed $5 \mathrm{~min}$ before, in addition to 0 , and $10 \mathrm{~min}$ after tourniquet deflation.

Results: The decrease of $\mathrm{rSO}_{2}$ was not significant during 20-min deflation period. MAP, CO and SV showed significant decrease during 2 to 12 , 4 to 6 and 2 to 6 -min period after tourniquet deflation, respectively $(\mathrm{P}<0.05)$. There was no relationship between a maximal decrease of $\mathrm{MAP}$ and $\mathrm{rSO}_{2}$.

Conclusions: In aged patients undergoing total knee replacement surgery under general anesthesia, tourniquet deflation caused significant changes in hemodynamic and metabolic status, but not in regional cerebral oxygen saturation. It is recommended to monitor neurologic status, as well as hemodynamic and metabolic status to avoid serious complications, especially in aged patients. (Korean J Anesthesiol 2012; 63: 425-430)

Key Words: Aged, Hemodynamics, Near-Infrared spectroscopy, Tourniquet.

Received: March 19, 2012. Revised: 1st, May 17, 2012; 2nd, June 7, 2012. Accepted: June 11, 2012.

Corresponding author: Dong Yeon Kim, M.D., Ph.D., Department of Anesthesiology and Pain Medicine, School of Medicine, Ewha Womans University, 911-1, Mok-dong, Yangcheon-gu, Seoul 158-710, Korea. Tel: 82-2-2650-5285, Fax: 82-2-2655-2924, E-mail: kdyeon@ewha.ac.kr (c) This is an open-access article distributed under the terms of the Creative Commons Attribution Non-Commercial License (http:// creativecommons.org/licenses/by-nc/3.0/), which permits unrestricted non-commercial use, distribution, and reproduction in any medium, provided the original work is properly cited. 


\section{Introduction}

As surgeries for aged patients are increasing consistently, total knee replacement surgery caused by internal derangement of the knee has also grown. Total knee replacement surgery is mainly performed in the aged with cardiopulmonary or cerebrovascular disease. A pneumatic tourniquet, used in total knee replacement surgery to minimize blood loss and secure a clean surgical field, may intensify the risk of complications like hypertension or hypotension, deep vein thrombosis, cerebral infarction, rhabdomyolsis, nerve injury, swelling or stiffness, hematoma, and infection; thus, meticulous care is important in anesthesia [1].

Compared with the average adult patients, the aged are more vulnerable to blood pressure regulation due to changes in autonomic nervous system and decrease in cardiac reserve. Therefore, sudden blood pressure fluctuation can be fatal to the aged even leading to cardiac or brain ischemia. Furthermore, various accompanying diseases may endanger the aged during anesthesia and perioperative period [2]. Inflation and deflation of a pneumatic tourniquet during surgery induces miscellaneous alterations in patient's hemodynamic and metabolic status. Especially, reperfusion to the exsanguinated area and bleeding from the surgical area, following tourniquet deflation, gives rise to hypotension, arterial oxygen and carbon dioxide partial pressure modification, lactic acidemia, and hyperkalemia $[1,3]$. Cerebral hypoperfusion secondary to hypotension may bring about postoperative cognitive dysfunction in the aged. Considering an increased possibility of several complications in the aged, appropriate monitoring becomes critical in anesthesia. Contrary to cardiovascular monitoring, such as electrocardiography, blood pressure, pulse oximetry, and arterial blood gas analysis performed routinely, monitoring for the central nervous system is rare, making it difficult to find out neurologic adverse events during general anesthesia. Nearinfrared spectroscopy (NIRS) is a noninvasive, continuous monitoring device, designed to estimate the regional cerebral oxygen saturation $\left(\mathrm{rSO}_{2}\right.$ ) by expressing the percentage between oxygenated and deoxygenated hemoglobin in the cerebral tissues. Accordingly, NIRS reflects a balance among cerebral oxygen supply and demand, enabling the effective surveillance for brain ischemia [4-6].

As the aged lack compensatory mechanism to adjust to hemodynamic changes, following tourniquet deflation, aggressive anesthetic management through active monitoring is essential. We evaluated the effect of tourniquet deflation on hemodynamics and regional cerebral oxygen saturation in the aged undergoing total knee replacement surgery, under general anesthesia, utilizing NIRS.

\section{Materials and Methods}

After obtaining approval from the Institutional Review Board and written informed consent, twenty-eight American Society of Anesthesiologists (ASA) physical status I or II patients, over the age of sixty-five years scheduled for total knee replacement surgery under general anesthesia, were enrolled in the study. Patients with a history of hypertension, stroke, heart failure or arrhythmia, chronic obstructive pulmonary disease, chronic kidney disease, and liver cirrhosis were excluded from the study.

No premedication was given. When patients arrived in the operating room, standard monitoring, including 3-lead electrocardiography, automatic noninvasive blood pressure, and peripheral pulse oximetry was attached in supine position. To measure the regional cerebral oxygen saturation $\left(\mathrm{rSO}_{2}\right)$, cerebral oximetry sensors (Adult SomaSensors ${ }^{\circledR}$, Somanetics, Troy, MI, USA) were placed bilaterally on the forehead $2 \mathrm{~cm}$ above the eyebrows with both diodes meeting at the center and connected to cerebral oximetry monitoring device (INVOS ${ }^{\circledR}$ System-Model 5100 , Somanetics, Troy, MI, USA). To monitor the arterial blood pressure continuously during the surgery and perform arterial blood gas analysis, 22 gauge catheter was inserted into the radial artery after modified Allen's test and cardiac output monitoring device (Vigileo/FloTrac ${ }^{\mathrm{TM}}$ System, Edwards Lifesciences, Irvine, CA, USA) was applied. Prior to induction of anesthesia, baseline data, including the mean arterial pressure (MAP), heart rate (HR), left and right $\mathrm{rSO}_{2}$, cardiac output (CO), and stroke volume (SV), were collected after $5 \mathrm{~min}$ of stabilizing period.

After 3 min of pre-oxygenation with 6 L of oxygen via a face mask, general anesthesia was induced with $0.04 \mathrm{mg} / \mathrm{kg}$ of midazolam, $0.2 \mathrm{mg}$ of glycopyrrolate, $4 \mathrm{mg} / \mathrm{kg}$ of thiopental sodium, and $1 \mu \mathrm{g} / \mathrm{kg}$ of fentanyl. When the patient's unconsciousness was confirmed, $0.6 \mathrm{mg} / \mathrm{kg}$ of rocuronium was given intravenously to facilitate endotracheal intubation, and the patient was manually ventilated with $100 \%$ oxygen for $90 \mathrm{~s}$ before intubation. Anesthesia was maintained with mixture of oxygen and nitrous oxide, at flow rate of $1.5 \mathrm{~L} / \mathrm{min}$ each. The end tidal sevoflurane concentration was adjusted to be between $1.0-2.0 \mathrm{vol} \%$. Initial tidal volume and respiratory rate was set as $10 \mathrm{ml} / \mathrm{kg}$ and $10 / \mathrm{min}$. The end tidal carbon dioxide partial pressure was adjusted between $30-35 \mathrm{mmHg}$. All patients maintained normothermia, using a warming device (Bair Hugger $^{\circledR}$ Warming Unit-Model 505, Arizant Healthcare Inc., Eden Prairie, MN, USA).

Before skin incision, a pneumatic tourniquet applied to the ipsilateral thigh was inflated to $350 \mathrm{mmHg}$. All monitoring data were recorded before induction of anesthesia and every $2 \mathrm{~min}$ after tourniquet deflation for $20 \mathrm{~min}$. Arterial blood gas analysis was performed $5 \mathrm{~min}$ before, and in addition to 0 , and $10 \mathrm{~min}$ 
after tourniquet deflation.

Statistical analysis was performed using SPSS (IBM ${ }^{\circledR}$ SPSS $^{\circledR}$ Statistics 20, SPSS Inc., IBM Corporation, Armonk, NY, USA) and all data were expressed as the mean \pm SD or absolute numbers. Repeated-measures ANOVA was used to compare the baseline data with the data at each time point. Linear regression analysis was used to determine the correlation between the maximal decrease of the mean arterial pressure and regional cerebral oxygen saturation, after converting the data according to the following formulas.

$$
\begin{aligned}
\cdot \% \triangle \mathrm{MAP}_{\max }= & {[(\text { baseline } \mathrm{MAP}-\text { measured minimal MAP }) /} \\
& \text { baseline } \mathrm{MAP}] \times 100 \\
\cdot \% \triangle \mathrm{rSO}_{2 \max }= & {\left[\left(\text { baseline } \mathrm{rSO}_{2}-\text { measured minimal } \mathrm{rSO}_{2}\right) /\right.} \\
& \text { baseline } \left.\mathrm{rSO}_{2}\right] \times 100
\end{aligned}
$$

\begin{tabular}{|c|c|c|}
\hline Variables & Data & Range \\
\hline Age (yr) & $72.5 \pm 4.0$ & $66-82$ \\
\hline $\operatorname{Sex}(M / F)$ & $9 / 19$ & \\
\hline Body weight (kg) & $66.3 \pm 9.7$ & $53-85$ \\
\hline Height (cm) & $157.1 \pm 7.1$ & $146-173$ \\
\hline $\operatorname{BMI}\left(\mathrm{kg} / \mathrm{m}^{2}\right)$ & $26.9 \pm 3.4$ & $21.4-35.1$ \\
\hline Duration of surgery (min) & $109.2 \pm 16.9$ & $80-150$ \\
\hline Duration of anesthesia (min) & $140.0 \pm 18.7$ & $105-185$ \\
\hline Duration of tourniquet time (min) & $66.7 \pm 14.4$ & $46-105$ \\
\hline Estimated blood loss (ml) & $508.9 \pm 252.0$ & $150-1,100$ \\
\hline Baseline left $\mathrm{rSO}_{2}(\%)$ & $66.0 \pm 8.9$ & $54-86$ \\
\hline Baseline right $\mathrm{rSO}_{2}(\%)$ & $65.4 \pm 9.1$ & $53-85$ \\
\hline Baseline MAP (mmHg) & $98.3 \pm 16.3$ & $70-135$ \\
\hline
\end{tabular}

A P value less than 0.05 was considered statistically significant.

Table 1. Demographic and Clinical Characteristics

Values are mean \pm SD or number of patients. BMI: Body mass index, $\mathrm{rSO}_{2}$ : regional cerebral oxygen saturation, MAP: mean arterial pressure.

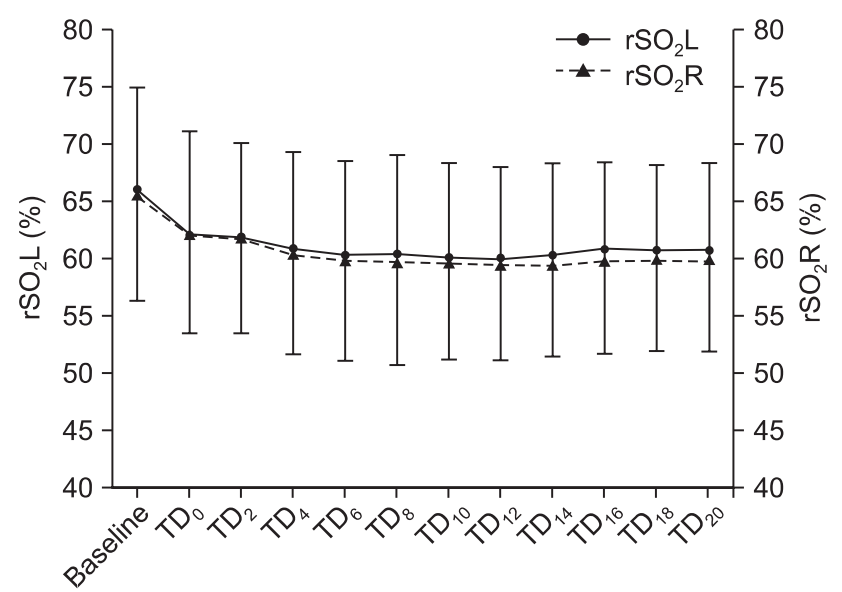

Fig. 1. Changes of left and right regional cerebral oxygen saturation during the 20 -min deflation period. $\mathrm{rSO}_{2} \mathrm{~L}$ : left regional cerebral oxygen saturation, $\mathrm{rSO}_{2} \mathrm{R}$ : right regional cerebral oxygen saturation, Baseline: before tourniquet inflation, $\mathrm{TD}_{0,2,4,6,8,10,12,14,16,18,20}: 0,2,4,6,8$, $10,12,14,16,18,20 \mathrm{~min}$ after tourniquet deflation. Values are mean \pm SD. There are no significant decreases compared to the baseline.

\section{Results}

The mean age of patients was $72.5 \pm 4.0$ years with 9 males and 19 females. Tourniquet inflation time was $66.7 \pm 14.4 \mathrm{~min}$. The baseline $\mathrm{rSO}_{2}$ checked before induction of anesthesia was $66.0 \pm 8.9 \%$ in the left and $65.4 \pm 9.1 \%$ in the right, showing no significant differences. The baseline MAP was $98.3 \pm 16.3 \mathrm{mmHg}$ (Table 1).

The decrease of $\mathrm{rSO}_{2}$ was not significant during a 20-min deflation period in both the left and right (Fig. 1). While MAP showed significant decrease during 2 to 12 -min period after

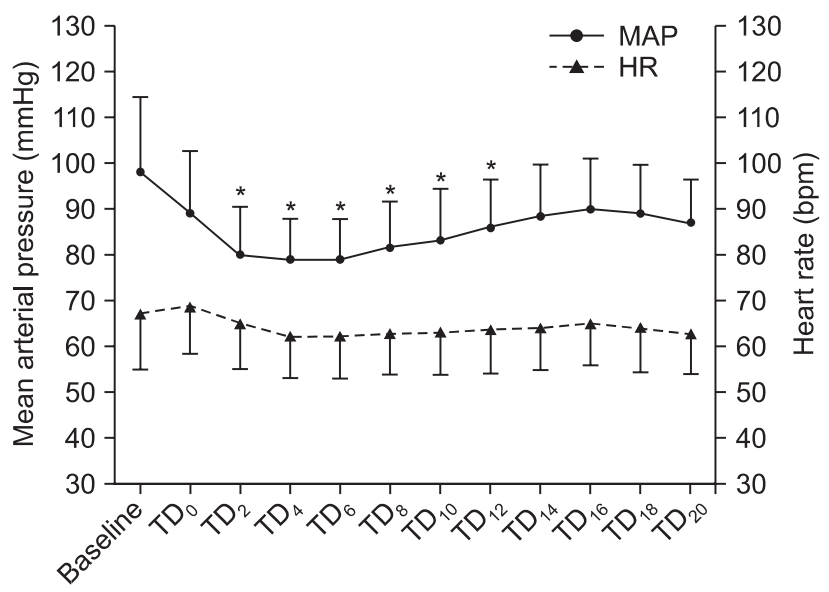

Fig. 2. Changes of mean arterial pressure and heart rate during the 20-min deflation period. MAP: mean arterial pressure, HR: heart rate, Baseline: before tourniquet inflation, $\mathrm{TD}_{0,2,4,6,8,10,12,14,16,18,20}: 0,2$, $4,6,8,10,12,14,16,18,20 \mathrm{~min}$ after tourniquet deflation. Values are mean $\pm \mathrm{SD}$. $* \mathrm{P}<0.05$ vs Baseline.

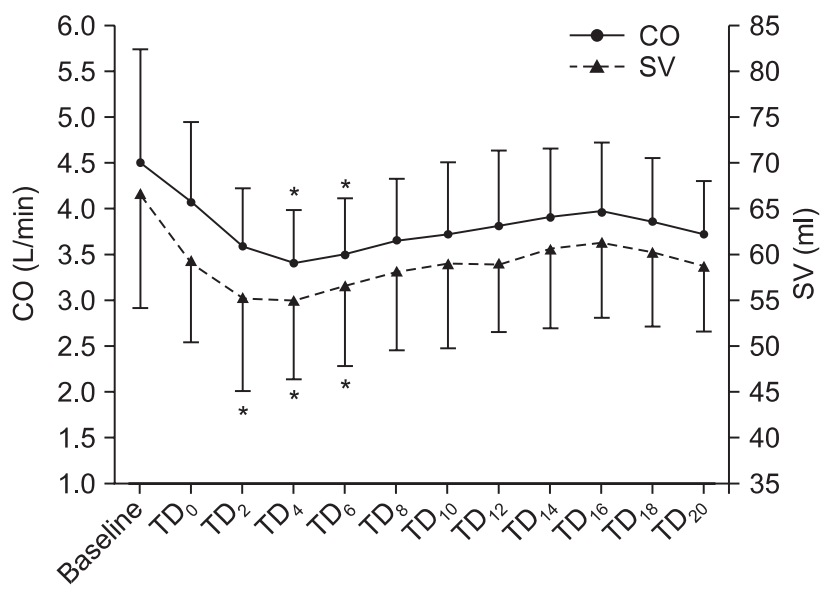

Fig. 3. Changes of cardiac output and stroke volume during the 20-min deflation period. CO: cardiac output, SV: stroke volume, Baseline: before tourniquet inflation, $\operatorname{TD}_{0,2,4,6,8,10,12,14,16,18,20}: 0,2,4$, $6,8,10,12,14,16,18,20 \mathrm{~min}$ after tourniquet deflation. Values are mean \pm SD. $* \mathrm{P}<0.05$ vs Baseline. 

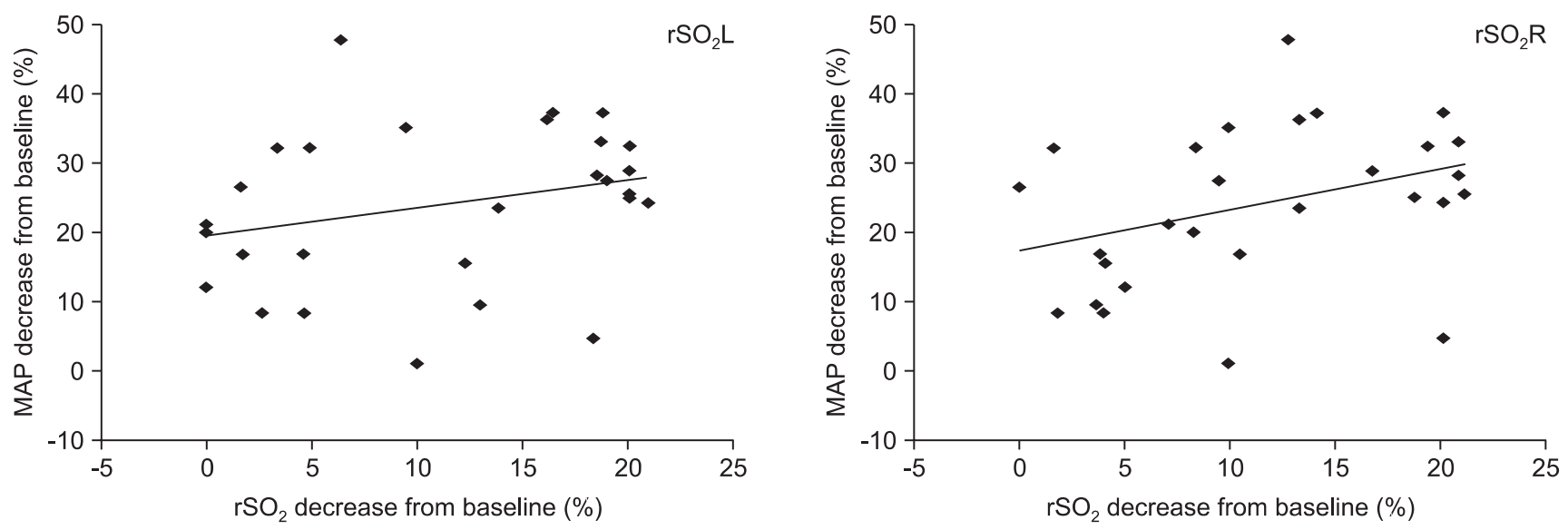

Fig. 4. Relationship between maximal decrease of mean arterial pressure and regional cerebral oxygen saturation from the baseline. MAP: mean arterial pressure, $\mathrm{rSO}_{2} \mathrm{~L}$ : left regional cerebral oxygen saturation, $\mathrm{rSO}_{2} \mathrm{R}$ : right regional cerebral oxygen saturation. There are no significant relationships.

Table 2. Changes in Arterial Blood Gas Analysis

\begin{tabular}{lcccccc}
\hline $\mathrm{pH}$ & $\begin{array}{c}\mathrm{PaCO}_{2} \\
(\mathrm{mmHg})\end{array}$ & $\begin{array}{c}\mathrm{PaO}_{2} \\
(\mathrm{mmHg})\end{array}$ & $\begin{array}{c}\text { Hemoglobin } \\
(\mathrm{g} / \mathrm{dl})\end{array}$ & $\begin{array}{c}\text { Lactate } \\
(\mathrm{mmol} / \mathrm{L})\end{array}$ & $\begin{array}{c}\text { Potassium } \\
(\mathrm{mmol} / \mathrm{L})\end{array}$ \\
\hline $\mathrm{TD}_{-5}$ & $7.40 \pm 0.03$ & $30.0 \pm 1.2$ & $235.1 \pm 18.7$ & $11.7 \pm 1.4$ & $1.4 \pm 0.5$ & $3.4 \pm 0.2$ \\
$\mathrm{TD}_{0}$ & $7.36 \pm 0.04^{*}$ & $35.8 \pm 2.5^{*}$ & $227.2 \pm 20.6^{*}$ & $11.4 \pm 1.4$ & $1.6 \pm 0.6^{*}$ & $3.5 \pm 0.3$ \\
$\mathrm{TD}_{10}$ & $7.35 \pm 0.02^{*}$ & $33.3 \pm 2.4^{*}$ & $226.5 \pm 21.4^{*}$ & $10.8 \pm 1.5^{*}$ & $1.9 \pm 0.7^{*}$ & $3.5 \pm 0.3$ \\
\hline
\end{tabular}

Values are mean $\pm \mathrm{SD} . \mathrm{PaO}_{2}$ : arterial $\mathrm{O}_{2}$ partial pressure, $\mathrm{PaCO}_{2}:$ arterial $\mathrm{CO}_{2}$ partial pressure, $\mathrm{TD}_{-5}: 5$ min before tourniquet deflation, $\mathrm{TD}_{0}$, $\mathrm{TD}_{10}: 0$, $10 \mathrm{~min}$ after tourniquet deflation. $* \mathrm{P}<0.05$ vs $\mathrm{TD}_{-5}$.

tourniquet deflation, HR showed no significant changes (Fig. 2). CO and SV decreased significantly during 4 to 6 and 2 to 6 -min period after tourniquet deflation, respectively (Fig. 3). There was no relationship between the maximal decrease of MAP and $\mathrm{rSO}_{2}$ in both the left and right (Fig. 4).

Arterial blood gas analysis showed a significant decrease in the $\mathrm{pH}$ and arterial oxygen partial pressure $\left(\mathrm{PaO}_{2}\right)$ immediately after tourniquet deflation, though remained normal. Arterial carbon dioxide partial pressure $\left(\mathrm{PaCO}_{2}\right)$ and lactate showed significant increase immediately after tourniquet deflation. Hemoglobin showed a significant decrease 10 min after tourniquet deflation. Potassium showed no significant changes (Table 2).

\section{Discussion}

The object of this study was to research the effect of tourniquet deflation on hemodynamics and regional cerebral oxygen saturation in the aged patients undergoing total knee replacement surgery, under general anesthesia. In the aged, functional disorders arising from the stiffened heart and blood vessels, decreased response to beta receptor stimulation, auto nomic imbalance or dysfunction, and impaired conducting system are common [2]. Although the central nervous system is considered as the primary endpoint of general anesthesia, perioperative central nervous system monitoring is seldom practiced. Perioperative neurological complications, including stroke, though rare with an incidence of $0.05-7 \%$, can be disastrous for the patient, its family, and the medical team [7]. Consequently, the necessity of the central nervous system monitoring has emerged. Transcranial Doppler (TCD), jugular bulb venous oxygen saturation, and somatosensory evoked potentials are being used currently [8]. Nevertheless, owing to its invasiveness and technical difficulty, general application remains controversial. Choi et al. [9] examined the changes in the brain activity during tourniquet deflation by measuring the bispectral index (BIS) and reported that BIS decreased during tourniquet deflation in patients undergoing knee arthroscopic surgery under general anesthesia, emphasizing proper monitoring for neurologically critical patients.

NIRS is a monitoring device designed to estimate the $\mathrm{rSO}_{2}$ non-invasively and continuously. By attaching a light-emitting diode (LED) on the scalp, which emits two different nearinfrared wavelengths into the skull, NIRS calculates the ratio of oxyhemoglobin to deoxyhemoglobin [5]. NIRS proved similar accuracy for the detection of cerebral ischemia, compared to 
the other invasive methods $[8,10]$. Hence, NIRS is appreciated as credible monitoring device that not only perceives variations in cerebral oxygenation caused by systemic hypoxemia, but also assesses the lowest limit for cerebral autoregulation [11].

Following tourniquet deflation, reperfusion to the exsanguinated lower extremities occurs and central venous pressure (CVP), MAP, and CO decreases as a result [12]. In this study, MAP, CO, and SV showed significant decrease during 2 to 12, 4 to 6 , and 2 to 6 -min period after tourniquet deflation, respectively. The effect of tourniquet deflation on HR varies in several reports. Cheong et al. [13] detected no significant changes in HR, whereas, Choi et al. [12] described that HR significantly increased in all groups (general anesthesia in control, epidural anesthesia in control, epidural anesthesia in elderly) except for general anesthesia in elderly group. In this study, HR showed no significant changes after tourniquet deflation. Townsend et al. [14] reported maximum changes in arterial $\mathrm{pH}, \mathrm{PaCO}_{2}$, potassium, lactate, and bicarbonate concentration, $3 \mathrm{~min}$ after tourniquet deflation. In this study, significant decrease in the $\mathrm{pH}$ and $\mathrm{PaO}_{2}$ accompanied by significant increase in $\mathrm{PaCO}_{2}$ and lactate were observed, immediately after tourniquet deflation. Hemoglobin showed significant decrease $10 \mathrm{~min}$ after tourniquet deflation, and potassium showed no significant changes. Meanwhile, as the changes above were all in normal range, $\mathrm{rSO}_{2}$ may not have been affected.

The $\mathrm{rSO}_{2}$ well reflects the cerebral oxygenation during hypoxemia, hypocapnia, hypercapnia, and hypotension, markedly making it valuable for the central nervous system monitoring during anesthesia and surgery, particularly in hypotensive episodes. Hypotension reduces cerebral blood flow, secondarily generates cerebral ischemia and may bring out adverse neurological outcomes [5]. Cerebral autoregulation refers to the ability of the brain to maintain a constant cerebral blood flow, despite changes in systemic blood pressure or cerebral perfusion pressure. Cerebral autoregulation typically operates between MAP of 60 and $150 \mathrm{mmHg}$ [15]. However, Schmidt et al. [16] claimed the lowest MAP for cerebral autoregulation to be $85 \pm 5 \mathrm{mmHg}$ in normal patients and $113 \pm 7$ $\mathrm{mmHg}$ in hypertensive patients. If MAP falls below the lowest limit for cerebral autoregulation, cerebral blood flow decreases, and so does the $\mathrm{rSO}_{2}$. Relationship between the decrease of $\mathrm{rSO}_{2}$ and MAP has not been clarified yet, causing controversies. Lee et al. [17] studied changes in $\mathrm{rSO}_{2}$ during the sitting position for shoulder arthroscopic surgery, and found no significant correlation between MAP and $\mathrm{rSO}_{2}$. Chu et al. [18] predicted changes of $\mathrm{rSO}_{2}$ based on the changes of MAP and HR in patients under spinal anesthesia, discovering that the effects of MAP and $\mathrm{HR}$ decrease on $\mathrm{rSO}_{2}$ lasted continuously for at least $6 \mathrm{~min}$. In this study, there was no relationship between the maximal decrease of MAP and $\mathrm{rSO}_{2}$ in both the left and right.
Aging acts as a prominent risk factor for perioperative neurologic complications [7] and the aged are sensitive to cerebral blood flow decline in particular. The $\mathrm{rSO}_{2}$ is known to be influenced by age, $\mathrm{PaCO}_{2}$, hemoglobin, cerebral blood flow, and changes in the cerebral metabolic rate. The normal range of $\mathrm{rSO}_{2}$ has not been established so far; Madsen et al. [19] insisted 55-78\%, and Kim et el. [20] asserted $71 \pm 6 \%$ in healthy volunteers, aged 20-36. Papadopoulos et al. [21] reported that the baseline $\mathrm{rSO}_{2}$ values have highly significant positive correlation with preoperative hematocrit and arterial hemoglobin oxygen saturation, but highly significant negative correlations with age and ASA classification. In this study, the decrease of $\mathrm{rSO}_{2}$ was not significant during 20-min deflation period in both the left and right. The minimum value of $\mathrm{rSO}_{2}$ was $60.1 \pm 7.1 \%$ in the left and $59.4 \pm 7.8 \%$ in the right. Tsuchiya et al. [22] recommended higher fraction of inspired oxygen to preserve cerebral oxygen delivery in the controlled hypotension during anesthesia. In this study, the arterial oxygen partial pressure maintained above $200 \mathrm{mmHg}$ might have contributed to an insignificant decrease in $\mathrm{rSO}_{2}$.

Reflecting only the $\mathrm{rSO}_{2}$ of specific part of the brain and wide variation among individuals affected by changes in the extracranial blood flow or sensor location have been pointed out as weaknesses of NIRS [23]. For that reason, recognizing the cerebral ischemia based on the changes in $\mathrm{rSO}_{2}$, rather than diagnosing cerebral ischemia by absolute $\mathrm{rSO}_{2}$ values, is considered worthwhile [5]. Casati et al. [24] stated the association between intraoperative cerebral desaturation and postoperative cognitive decline. Samra et al. [25] discovered $20 \%$ decrease in $\mathrm{rSO}_{2}$ from the baseline as a predictor of neurologic compromise. Regarding the insignificant decrease in the $\mathrm{rSO}_{2}$ after tourniquet deflation and the minimum $\mathrm{rSO}_{2}$ values measured in this study, tourniquet deflation may not escalate the risk of neurologic complications solely. Nonetheless, further studies on multiple factors influencing the $\mathrm{rSO}_{2}$ are needed.

In conclusion, tourniquet deflation created significant hemodynamic and metabolic changes in the aged undergoing total knee replacement surgery under general anesthesia. The $\mathrm{rSO}_{2}$ decreased, but insignificantly and no relationship between MAP and $\mathrm{rSO}_{2}$ was found. Still, since the aged lack compensatory mechanism to adjust to dynamic changes, aggressive anesthetic management through active monitoring is crucial.

\section{References}

1. Wakai A, Winter DC, Street JT, Redmond PH. Pneumatic tourniquets in extremity surgery. J Am Acad Orthop Surg 2001; 9: 345-51.

2. Sieber FE, Pauldine R. Geriatric anesthesia. In: Miller's anesthesia. 7th ed. Edited by Miller RD, Eriksson LI, Fleisher LA, WienerKronish JP, Young WL: Philadelphia, Churchill Livingstone. 2010, pp 2261-76. 
3. Oh HJ, Choi YW, Sung CH, Moon SH, Kim SN, Chung WH. The changes of metabolic and acid-base status and respiratory gases elicited by pneumatic tourniquet for lower extremity surgery. Korean J Anestheisol 1991; 24: 628-34.

4. Casati A, Spreafico E, Putzu M, Fanelli G. New technology for noninvasive brain monitoring: continuous cerebral oximetry. Minerva Anestesiol 2006; 72: 605-25.

5. Williams IM, Mortimer AJ, McCollum CN. Recent developments in cerebral monitoring-near-infrared light spectroscopy. An overview. Eur J Vasc Endovasc Surg 1996; 12: 263-71.

6. Murkin JM, Arango M. Near-infrared spectroscopy as an index of brain and tissue oxygenation. Br J Anaesth 2009; 103 Suppl 1: i3-13.

7. Ng JL, Chan MT, Gelb AW. Perioperative stroke in noncardiac, nonneurosurgical surgery. Anesthesiology 2011; 115: 879-90.

8. Moritz S, Kasprzak P, Arlt M, Taeger K, Metz C. Accuracy of cerebral monitoring in detecting cerebral ischemia during carotid endarterectomy: a comparison of transcranial doppler sonography, nearinfrared spectroscopy, stump pressure, and somatosensory evoked potentials. Anesthesiology 2007; 107: 563-9.

9. Choi JH, Sung JK, Park SW, Kang WJ. Effects of the tourniquet deflation on bispectral index during knee arthroscopic surgery under the general anesthesia. Korean J Anesthesiol 2009; 56: 371-4.

10. Pollard V, Prough DS, DeMelo AE, Deyo DJ, Uchida T, Stoddart HF. Validation in volunteers of a near-infrared spectroscope for monitoring brain oxygenation in vivo. Anesth Analg 1996; 82: 269-77.

11. Olsen KS, Svendsen LB, Larsen FS. Validation of transcranial near-infrared spectroscopy for evaluation of cerebral blood flow autoregulation. J Neurosurg Anesthesiol 1996; 8: 280-5.

12. Choi Y, Yang HS, Park SE, Kim DY, Kim HK. Tourniquet induced hypertension and vital sign changes in elderly patients associated with tourniquet use under general or epidural anesthesia for total knee arthroplasty. Korean J Anesthesiol 1999; 36: 653-9.

13. Cheong MA, Koh MS, Yang HS. Effects of four anesthesia methods and tourniquet durations on tourniquet induced hypertension during total knee arthroplasty. Korean J Anesthesiol 2002; 42: 312-7.

14. Townsend HS, Goodman SB, Schurman DJ, Hackel A, Brock-Utne JG. Tourniquet release: systemic and metabolic effects. Acta Anaesthesiol Scand 1996; 40: 1234-7.
15. Paulson OB, Strandgaard S, Edvinsson L. Cerebral autoregulation. Cerebrovasc Brain Metab Rev 1990; 2: 161-92.

16. Schmidt JF, Waldemar G, Vorstrup S, Andersen AR, Gjerris F, Paulson OB. Computerized analysis of cerebral blood flow autoregulation in humans: validation of a method for pharmacologic studies. J Cardiovasc Pharmacol 1990; 15: 983-8.

17. Lee DH, Choi JH, Lee DI, Choi YK. Changes in blood pressure, heart rate and regional cerebral oxygen saturation during the sitting position for shoulder arthroscopic surgery. Korean J Anesthesiol 2008; 55: 46-51.

18. Chu LC, Hsu YW, Lee TC, Lin YC, Huang CJ, Chen CC, et al. Changes of regional cerebral oxygen saturation during spinal anesthesia. Acta Anaesthesiol Taiwan 2007; 45: 155-62.

19. Madsen PL, Nielsen HB, Christiansen P. Well-being and cerebral oxygen saturation during acute heart failure in humans. Clin Physiol 2000; 20: 158-64.

20. Kim MB, Ward DS, Cartwright CR, Kolano J, Chlebowski S, Henson LC. Estimation of jugular venous $\mathrm{O}_{2}$ saturation from cerebral oximetry or arterial $\mathrm{O}_{2}$ saturation during isocapnic hypoxia. J Clin Monit Comput 2000; 16: 191-9.

21. Papadopoulos G, Karanikolas M, Liarmakopoulou A, Berris A. Baseline cerebral oximetry values in elderly patients with hip fractures: a prospective observational study. Injury 2011; 42: 132832.

22. Tsuchiya M, Tokai H, Imazu Y, Arai K, Manabe M. Effect of controlled hypotension on cerebral oxygen delivery. Masui 1997; 46: 910-4.

23. Kishi K, Kawaguchi M, Yoshitani K, Nagahata T, Furuya H. Influence of patient variables and sensor location on regional cerebral oxygen saturation measured by INVOS 4100 near-infrared spectrophotometers. J Neurosurg Anesthesiol 2003; 15: 302-6.

24. Casati A, Fanelli G, Pietropaoli P, Proietti R, Tufano R, Danelli G, et al. Continuous monitoring of cerebral oxygen saturation in elderly patients undergoing major abdominal surgery minimizes brain exposure to potential hypoxia. Anesth Analg 2005; 101: 740-7.

25. Samra SK, Dy EA, Welch K, Dorje P, Zelenock GB, Stanley JC. Evaluation of a cerebral oximeter as a monitor of cerebral ischemia during carotid endarterectomy. Anesthesiology 2000; 93: 964-70. 